\title{
Bovine coronavirus in Uruguay: genetic diversity, risk factors and transboundary introductions from neighboring countries
}

\author{
Matías Castells $s^{1,2} \cdot$ Federico Giannitti $^{2} \cdot$ Rubén Darío Caffarena $^{2,3} \cdot$ María Laura Casaux $^{2} \cdot$ Carlos Schild $^{2}$. \\ Daniel Castells ${ }^{4} \cdot$ Franklin Riet-Correa $^{2} \cdot$ Matías Victoria $^{1} \cdot$ Viviana Parreño $^{5} \cdot$ Rodney Colina $^{1}$ (D)
}

Received: 26 June 2019 / Accepted: 30 July 2019 / Published online: 27 August 2019

(C) Springer-Verlag GmbH Austria, part of Springer Nature 2019

\begin{abstract}
Bovine coronavirus $(\mathrm{BCoV})$ is a recognized cause of severe neonatal calf diarrhea, with a negative impact on animal welfare, leading to economic losses to the livestock industry. Cattle production is one of the most important economic sectors in Uruguay. The aim of this study was to determine the frequency of $\mathrm{BCoV}$ infections and their genetic diversity in Uruguayan calves and to describe the evolutionary history of the virus in South America. The overall detection rate of BCoV in Uruguay was 7.8\% (64/824): 7.7\% (60/782) in dairy cattle and 9.5\% (4/42) in beef cattle. The detection rate of BCoV in samples from deceased and live calves was $10.0 \%(6 / 60)$ and 7.6\% (58/763), respectively. Interestingly, there was a lower frequency of $\mathrm{BCoV}$ detection in calves born to vaccinated dams $(3.3 \%, 8 / 240)$ than in calves born to unvaccinated dams $(12.2 \%, 32 / 263)$ (OR: $4.02,95 \%$ CI: $1.81-8.90 ; p=0.00026)$. The frequency of BCoV detection was higher in colder months $(11.8 \%, 44 / 373)$ than in warmer months $(1.5 \%, 3 / 206)$ (OR: 9.05, 95\%CI: $2.77-29.53, p=0.000013)$. Uruguayan strains grouped together in two different lineages: one with Argentinean strains and the other with Brazilian strains. Both BCoV lineages were estimated to have entered Uruguay in 2013: one of them from Brazil (95\%HPD interval: 2011-2014) and the other from Argentina (95\%HPD interval: 2010-2014). The lineages differed by four amino acid changes, and both were divergent from the Mebus reference strain. Surveillance should be maintained to detect possible emerging strains that can clearly diverge at the antigenic level from vaccine strains.
\end{abstract}

Handling Editor: Zhenhai Chen.

Rubén Darío Caffarena and María Laura Casaux, Carlos Schild contribute equally to this work.

Electronic supplementary material The online version of this article (https://doi.org/10.1007/s00705-019-04384-w) contains supplementary material, which is available to authorized users.

Rodney Colina

rodneycolina1@gmail.com

1 Laboratorio de Virología Molecular, CENUR Litoral Norte, Centro Universitario de Salto, Universidad de la República, Rivera 1350, 50000 Salto, Uruguay

2 Instituto Nacional de Investigación Agropecuaria (INIA), Plataforma de Investigación en Salud Animal, Ruta 50 km 11, La Estanzuela, 70000 Colonia, Uruguay

3 Facultad de Veterinaria, Universidad de la República, Alberto Lasplaces 1620, Montevideo, Uruguay

4 Centro de Investigación y Experimentación Dr. Alejandro Gallinal, Secretariado Uruguayo de la Lana, Ruta 7 km 140, Cerro Colorado, Florida, Uruguay

5 Sección de Virus Gastroentéricos, Instituto de Virología, CICV y A, INTA Castelar, Buenos Aires, Argentina

\section{Introduction}

Bovine coronavirus $(\mathrm{BCoV})$ is recognized as a cause of severe neonatal calf diarrhea (NCD), respiratory tract infections in calves, and winter dysentery in adult cattle [1]. NCD has a negative impact on animal welfare and leads to economic losses to the livestock industry due to the costs of treatment and prophylaxis, increased susceptibility to other diseases, increased mortality, and long-term residual effects, such as reduced growth rates and milk production [2-5]. Neonatal calf diarrhea is the major cause of death in unweaned heifers [6].

Cattle production is one of the main economic sectors in Uruguay, accounting for $33 \%$ of the exports and $5 \%$ of the gross domestic product, with 11,739,000 head of cattle [7]. Worldwide, Uruguay is one of the main exporters of bovine meat [8] and dairy products [9].

Bovine CoV belongs to the species Betacoronavirus 1, which was recently assigned by the International Committee on Taxonomy of Viruses (ICTV) to the order Nidovirales, suborder Cornidovirineae, family Coronaviridae, 
subfamily Orthocoronavirinae, genus Betacoronavirus, and subgenus Embecovirus [10]. Members of the species Betacoronavirus 1 infect not only cattle and wild ruminants [11] but also other mammals such as equids (equine coronavirus) [12], humans (human coronavirus OC43) and pigs (porcine hemagglutinating encephalomyelitis virus) [13].

Bovine CoV has a 32-kb, single-stranded, positive-sense RNA genome - the largest among known RNA viruses [13]. Bovine $\mathrm{CoV}$ viral particles are enveloped and pleomorphic and contain five structural proteins. Four are external and glycosylated: the transmembrane (M), the small envelope (E), the hemagglutinin-esterase (HE) and the spike (S) proteins. The other, the nucleocapsid $(\mathrm{N})$ protein, is internal $[14,15]$.

The biological functions of the $\mathrm{S}$ protein of $\mathrm{CoV}$ include primary attachment to target cells and membrane fusion. The $\mathrm{S}$ protein is cleaved to produce the $\mathrm{N}$-terminal $\mathrm{S} 1$ and $\mathrm{C}$-terminal S2 glycopolypeptides. The hypervariable region within S1 is associated with some of the antigenic differences, being the major inducer of virus-neutralizing antibodies, and may also be associated with host range and tissue tropism. Most of the differences in $\mathrm{S} 1$ occur between virulent and non-virulent strains [16]. The hypervariable S1 genomic region has been widely used to study the genetic variability and evolution of the virus, including the few studies on molecular characterization of $\mathrm{BCoV}$ strains conducted in the South American region [17-19].

To date, little is known about the genetic diversity of $\mathrm{BCoV}$ in South America, where the few studies that have been done were mainly restricted to Brazil and Argentina, as mentioned above, and information about its evolutionary history in this region is lacking in the scientific literature. Furthermore, the genetic diversity of $\mathrm{BCoV}$ in Uruguay has not been investigated.

The aim of this study was to determine the frequency of $\mathrm{BCoV}$ infection in Uruguayan calves, to examine the genetic diversity of the virus, to identify risk factors associated with the frequency of $\mathrm{BCoV}$ detection, and to investigate the evolutionary history of $\mathrm{BCoV}$ in the South American region through phylogenetic, phylodynamic, and phylogeographic analyses.

\section{Materials and methods}

\section{Sample collection and fecal suspensions}

A total of 824 samples of feces (763) and intestinal contents (61) were obtained from beef and dairy cattle in Uruguay between July 2015 and December 2017; additional information on sample origins is detailed in Table 1 and Fig. 1. A

Table 1 Sample information

\begin{tabular}{cllllllllllllllll}
\hline & \multicolumn{1}{c}{ Diarrhea } & \multicolumn{4}{l}{$\begin{array}{l}\text { Exploitation } \\
\text { type }\end{array}$} & \multicolumn{1}{l}{ Age (days) } & & \multicolumn{3}{c}{$\begin{array}{l}\text { Dams } \\
\text { vaccinated }^{1}\end{array}$} \\
\hline & Yes & No & ND & Dairy & Beef & $1-7$ & $8-14$ & $15-21$ & $22-28$ & $>28$ & ND & Yes & No & ND \\
$\mathrm{n}$ & 266 & 297 & 261 & 782 & 42 & 153 & 220 & 113 & 38 & 20 & 280 & 240 & 263 & 321 \\
\hline
\end{tabular}

ND: not determined

${ }^{1}$ Vaccination against neonatal calf diarrhea. Most available vaccines in the Uruguayan market include bovine coronavirus
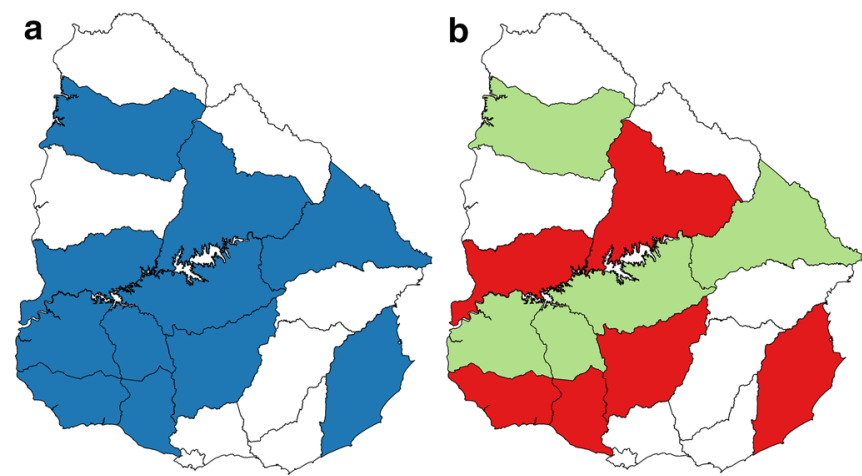

Fig. 1 Map of Uruguay showing the 19 departments into which the country is divided. a) Sampling. b) Rate of $\mathrm{BCoV}$ detection in beef and dairy cattle combined. c) Rate of $\mathrm{BCoV}$ detection in beef cattle. d) Rate of $\mathrm{BCoV}$ detection in dairy cattle. Departments from which
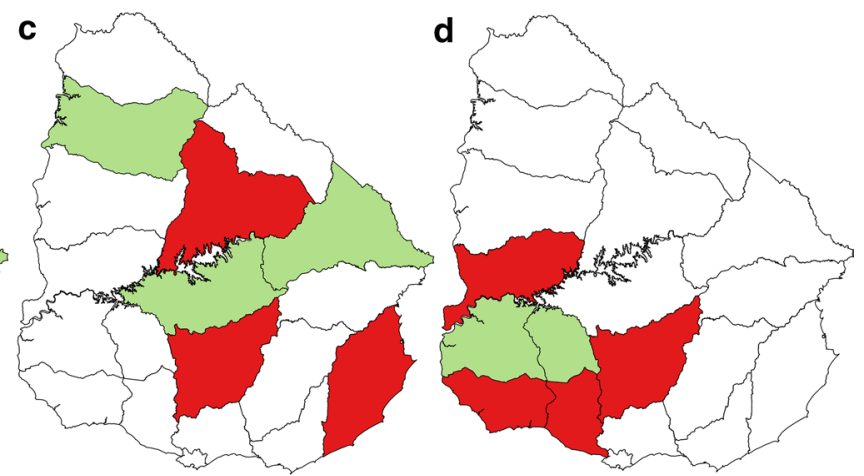

samples were obtained are shown in blue, those in which BCoV was detected are shown in red, and those in which $\mathrm{BCoV}$ was not detected are shown in green 
survey conducted to collect information about management and problems associated with dairy cattle farming (the farms were randomly selected and representative of the dairy area in southwestern Uruguay) and the intensive production system facilitated the collection of a large number of samples (782). On the other hand, beef cattle sampling was carried out by personal contact with farmers in order to encompass as many departments (geographic regions) as possible, but the extensive production system of beef cattle in Uruguay hindered access to the samples (42), and this is a limitation of this work. Samples were diluted 1:10 (v:v) in phosphatebuffered saline solution and centrifuged at $3000 \mathrm{~g}$ for 20 minutes at $4{ }^{\circ} \mathrm{C}$, and supernatants were collected and stored at $-80{ }^{\circ} \mathrm{C}$

\section{RNA extraction and reverse transcription}

Viral RNA was extracted using a QIAamp cador Pathogen Mini Kit (QIAGEN), following the manufacturer's instructions. Reverse transcription (RT) was carried out using RevertAid Reverse Transcriptase (Thermo Fischer Scientific) and random hexamers primers (QIAGEN) following the manufacturer instructions. All RNAs and cDNAs were stored at $-80^{\circ} \mathrm{C}$.

\section{Polymerase chain reaction assay for bovine coronavirus}

The initial screening of the samples for identification of $\mathrm{BCoV}$ was carried out using a real-time polymerase chain reaction (PCR) targeted the $\mathrm{S}$ gene, following a standard operating procedure kindly provided by Dr. Stephanie Rossow from the University of Minnesota Veterinary Diagnostic Laboratory. Briefly, $12.5 \mu \mathrm{L}$ of SensiFAST ${ }^{\mathrm{TM}}$ Probe No-ROX Kit (Bioline), $1.0 \mu \mathrm{L}$ of $10 \mu \mathrm{M}$ BCoV Minn F primer (TGTTTTAAAGCTTCCACAAATTTCTG), $1.0 \mu \mathrm{L}$ of $10 \mu \mathrm{M}$ BCoV Minn R primer (AACCAGCATCTATAC CAGGACCAT), $0.5 \mu \mathrm{L}$ of $10 \mu \mathrm{M}$ BCoV Minn S probe (Cy5-CGTGTAAATTGGATGGGTCTTTGTGTGTAG GT-BHQ-2) and 5.0 $\mu \mathrm{L}$ of nuclease-free water were mixed in $0.2-\mathrm{mL}$ PCR tubes. The PCR cycling conditions were $95^{\circ} \mathrm{C}$ for 10 minutes, followed by 45 cycles of $95^{\circ} \mathrm{C}$ for 15 seconds and $50{ }^{\circ} \mathrm{C}$ for 45 seconds.

In order to obtain sequences for evolutionary analysis, positive samples detected by the real-time PCR assay were further amplified using a heminested PCR targeting to the $S$ gene, using primers described elsewhere [17]. Briefly, for the first round of the heminested PCR, $12.5 \mu \mathrm{L}$ of Mango$\mathrm{Mix}^{\mathrm{TM}}$ (Bioline), $5 \mu \mathrm{L}$ of cDNA, $3.9 \mu \mathrm{L}$ of nuclease-free water, $1 \mu \mathrm{L}$ of dimethyl sulfoxide, $1.3 \mu \mathrm{L}$ of $10 \mu \mathrm{M}$ S1NS primer, and $1.3 \mu \mathrm{L}$ of $10 \mu \mathrm{M}$ primer S1HA were mixed in $0.2-\mathrm{mL}$ PCR tubes and subjected to an initial step of $5 \mathrm{~min}$ utes at $95{ }^{\circ} \mathrm{C}$, followed by 35 cycles of $94{ }^{\circ} \mathrm{C}$ for 1 minute,
$53.4{ }^{\circ} \mathrm{C}$ for 1 minute, and $72{ }^{\circ} \mathrm{C}$ for 1 minute, ending with 10 minutes at $72{ }^{\circ} \mathrm{C}$ for final extension. For the second round, $12.5 \mu \mathrm{L}$ of MangoMix ${ }^{\mathrm{TM}}$ (Bioline), $2 \mu \mathrm{L}$ of the $\mathrm{PCR}$ product from the first round, $7.5 \mu \mathrm{L}$ of nuclease-free water, $1 \mu \mathrm{L}$ of dimethyl sulfoxide, $1 \mu \mathrm{L}$ of $10 \mu \mathrm{M}$ S1NS primer, and $1 \mu \mathrm{L}$ of $10 \mu \mathrm{M}$ primer S1NAS were mixed in $0.2-\mathrm{mL}$ PCR tubes and subjected to an initial step of 5 minutes at $95{ }^{\circ} \mathrm{C}$, followed by 40 cycles of $94{ }^{\circ} \mathrm{C}$ for 1 minute, $58.4{ }^{\circ} \mathrm{C}$ for 1 minute and $72{ }^{\circ} \mathrm{C}$ for 1 minute, ending with 10 minutes at $72{ }^{\circ} \mathrm{C}$ for final extension. The predicted PCR products were $785 \mathrm{bp}$ and 488 bp long for first and second round, respectively (modified from reference 17).

\section{Purification and sequencing of PCR products}

PCR products were visualized in $2 \%$ agarose gels, and positive samples were purified using a PureLink ${ }^{\mathrm{TM}}$ Quick Gel Extraction and PCR Purification Combo Kit (Invitrogen) according to the manufacturer's instructions, and both DNA strands were sequenced by Macrogen Inc. (Seoul, South Korea). Sequences were deposited in the GenBank database with accession numbers MK318150-MK318179.

\section{Phylogenetic analysis}

Partial spike sequences were downloaded from GenBank (https://www.ncbi.nlm.nih.gov/genbank/, Table S1) and, together with the Uruguayan sequences obtained in this study, were aligned using Clustal W, implemented in MEGA 7 software [20]. A curated alignment of 443 nucleotides (nt) was obtained (corresponding to positions 24,984-25,426 of the Mebus strain). The nucleotide substitution model that best fit the alignment (TIM $3+\mathrm{I}+\mathrm{G}_{4}$ ) was chosen and a maximum-likelihood tree was constructed using W-IQ-TREE (available at http://iqtree.cibiv.univie.ac.at) [21]. The branch support was estimated using the approximate likelihoodratio test (aLRT) [22].

\section{Phylodynamic and phylogeographic analysis}

Considering that South American strains grouped together in two lineages, all of the available sequences of the $\mathrm{S}$ region of the BCoV genome available in GenBank from South America were downloaded (Table S2), although some of the Brazilian and Argentinean sequences were shorter than the ones obtained in our study. In order to include these sequences from the South American region, the fragment used for evolutionary analysis was smaller than that used for phylogenetic analysis. Sequences were aligned using Clustal W implemented in MEGA 7 software [20], and an alignment of $332 \mathrm{nt}$ was obtained (corresponding to positions 25,021-25,352 of the Mebus strain). The temporal structure of the dataset was evaluated using TempEst [23]. The 
substitution model that best fit the alignment was determined using MEGA 7 software, and used as prior (TN93, [24]) in the analysis implemented in the BEAST v1.8.4 package [25]. Combinations of molecular clocks (strict, relaxed lognormal and relaxed exponential) and coalescent tree priors (constant, exponential, and skyline) were evaluated using Bayes factors. The uncorrelated relaxed with exponential distribution molecular clock and the Bayesian Skyline coalescent model were selected, and the country location was used as a trait for the phylogeographic analysis. The Markov chain Monte Carlo length was 200 million generations, obtaining 10,000 parameters samples. Effective sample size (ESS) was evaluated in Tracer v1.6.0, and ESS values higher than 200 for all parameters were accepted.

A maximum clade credibility tree (MCCT) was obtained using TreeAnnotator software from the BEAST v.1.8.4 package and visualized in FigTree v1.4.3. A Bayesian Skyline plot was generated using Tracer v1.6.0.

\section{Signature patterns distinguishing Uruguayan lineages}

Viral Epidemiology Signature Pattern Analysis (VESPA) [26], available at: https://www.hiv.lanl.gov/content/seque nce/VESPA/vespa.html) was used to detect patterns that could differentiate the lineages of $\mathrm{BCoV}$ circulating in Uruguayan cattle, using only the local strains and the translated alignment obtained for the phylogenetic analysis (the first nucleotide was excluded to have an in-frame translation). Moreover, both lineages were compared with the reference strain Mebus, which is used in the vaccines currently available on the market.

\section{Statistical analysis}

Data were organized and graphics were generated using Microsoft Office Excel. Categorical data were evaluated using Pearson's chi-squared test with jamovi software (available at: https://www.jamovi.org/). Differences were considered statistically significant if the $p$-value was lower than 0.05 . Odds ratios (OR) and $95 \%$ confident intervals (CI) were calculated for groups with statistically significant differences, using jamovi software. In multiple comparison Chi-square tests, the Bonferroni correction was applied.

\section{Results}

\section{Frequency of $\mathrm{BCoV}$ detection in Uruguay}

The study covered 11 departments of the 19 into which Uruguay is geographically divided (Fig. 1a). Bovine $\mathrm{CoV}$ was detected in 6 out of 11 departments (55\%) (Fig. 1b); the frequency of detection in each department was as follows: $6.9 \%$ (8/116) in Colonia, $7.1 \%(2 / 28)$ in Florida, $14.7 \%$ (21/143) in Río Negro, 22.2\% (2/9) in Rocha, 6.4\% $(15 / 233)$ in San José, and $12.5 \%$ (1/8) in Tacuarembó. $\mathrm{BCoV}$ was detected in 3 of the 6 departments sampled for beef cattle (50\%) (Fig. 1c), and 4 of the 6 departments sampled for dairy cattle (67\%) (Fig. 1d).

The overall detection rate of $\mathrm{BCoV}$ in Uruguay was $7.8 \%$ (64/824). The frequency of BCoV detection in dairy and beef cattle was 7.7\% (60/782) and 9.5\% (4/42), respectively (Fig. 2a); this difference was not statistically significant $(p=0.69)$. The detection rate of $\mathrm{BCoV}$ in samples from deceased calves $(10.0 \%, 6 / 60)$ was higher than in samples from live calves $(7.6 \%, 58 / 763)$, although this difference was not statistically significant $(p=0.50)$ (Fig. 2b).

Interestingly, calves born to unvaccinated dams showed higher frequency of $\mathrm{BCoV}$ infection $(12.2 \%, 32 / 263)$ than calves born to vaccinated dams $(3.3 \%, 8 / 240)$. This difference was statistically significant (OR: $4.02,95 \% \mathrm{CI}$ : 1.81-8.9; $p=0.00026$ ) (Fig. 2c).

As shown in Fig. 2d, BCoV was detected in $6.5 \%$ (10/153), 5.5\% (12/220), 11.5\% (13/113), 18.4\% (7/38), and $15.0 \%$ (3/20) of the calves in the first, second, third, and fourth week and after the fourth week of life, respectively. A statistically significant difference was observed between the second and the fourth week of age (OR: 3.91, 95\% CI: 1.43-10.70; $p=0.0047)$. No statistical differences were observed between $\mathrm{BCoV}$ frequency of detection and diarrhea when all age groups were analyzed together: $6.5 \%$ $(17 / 263)$ in diarrheic and $10.8 \%$ (32/295) in non-diarrheic calves ( $p=0.068$ ), however, in the first week of calves' life, the $\mathrm{BCoV}$ detection rate was statistical higher in diarrheic $12.1 \%(7 / 58)$ than non-diarrheic 3.2\% (3/92) calves (OR: $4.21,95 \%$ CI: $1.04-16.99 ; p=0.030$ ). In the other age groups, the $\mathrm{BCoV}$ frequency was lower in diarrheic versus non-diarrheic calves: $3.9 \%$ (6/152) vs. $8.8 \%(6 / 68), 2.9 \%$ (1/34) vs. $15.2 \%(12 / 79), 14.3 \%$ (1/7) vs. $19.4 \%(6 / 31)$ and $12.5 \%$ (1/8) vs. $16.7 \%$ (2/12), in the second, third, and fourth week, and after the fourth week of life, respectively, but no statistically significant differences were observed.

As shown in Fig. 2e, BCoV was detected with a seasonal distribution, mainly in June, July and August, which are the coldest months in Uruguay. In addition, two groups were analyzed based on monthly average temperature using a cutoff value of $13{ }^{\circ} \mathrm{C}$ considering that the mean monthly temperature is below the cutoff in June, July and August and above the cutoff in the rest of the months. The frequency of $\mathrm{BCoV}$ detection was significantly higher in the months with average temperature $<13{ }^{\circ} \mathrm{C}$ $(11.8 \%, 44 / 373)$ than in those with an average temperature $>13{ }^{\circ} \mathrm{C}(1.5 \%, 3 / 206)$ (OR: 9.05, 95\% CI: 2.77-29.53, $p=0.000013)$. 

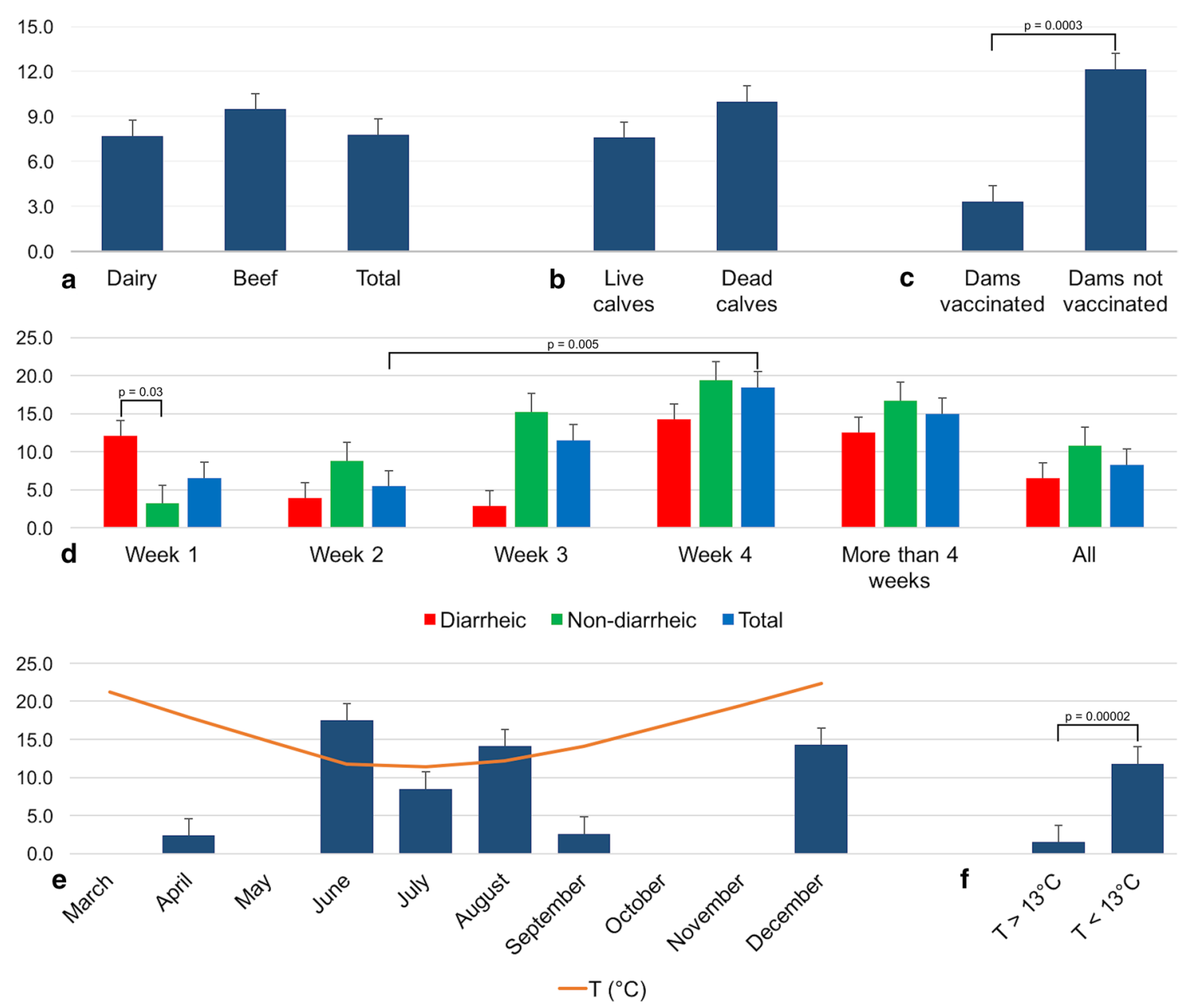

Fig. 2 Comparison of $\mathrm{BCoV}$ detection rates in different groups. a) Frequency of $\mathrm{BCoV}$ detection in beef vs. dairy cattle. b) Frequency of $\mathrm{BCoV}$ detection in live vs. dead calves. c) Frequency of $\mathrm{BCoV}$ detection in calves born to vaccinated vs. unvaccinated dams. d) Frequency of $\mathrm{BCoV}$ detection according to the age in weeks in diar-

\section{Phylogenetic analysis}

In Fig. 3, the phylogenetic relationship between the Uruguayan $\mathrm{BCoV}$ strains and those for which sequences were obtained from the GenBank database is shown. Geographically associated (continent-specific) lineages were observed, and Uruguayan strains grouped in the two South American lineages, one of them with Argentinean strains and the other with Brazilian strains.

\section{Phylodynamic and phylogeographic analysis of BCoV in South America}

An MCCT (Fig. 4a) also showed that the Uruguayan BCoV strains grouped together in two different lineages: one with Argentinean and the other with Brazilian strains. The rheic and non-diarrheic calves, and the total number of calves. e) Frequency of $\mathrm{BCoV}$ detection according to the month of sampling. f) Frequency of $\mathrm{BCoV}$ detection according to the ambient temperature. Comparisons between groups with statistically significant differences are shown

substitution rate estimated in this analysis was $1.39 \times 10^{-3}$ substitutions/site/year (s/s/y) (95\% highest posterior density [95\%HPD] interval: $8.3 \times 10^{-4}-2.0 \times 10^{-3}$ ), and the most recent common ancestor (MRCA) of each lineage was dated to 1992 (95\%HPD interval: 1985-1994) located in Argentina with a probability of 0.99 , and in 2000 (95\%HPD interval: 1994-2002) located in Brazil with a probability of 0.99 . More information about key nodes is detailed in Table 2.

These $\mathrm{BCoV}$ lineages were estimated to have entered Uruguay in 2013: one of them from Brazil (95\%HPD interval: 2011-2014) and the other from Argentina (95\%HPD interval: 2010-2014) (Fig. 4c).

A Bayesian skyline plot showed that the population size of $\mathrm{BCoV}$ in South America was constant in the last two decades, with some minor fluctuations (Fig. 4b). 


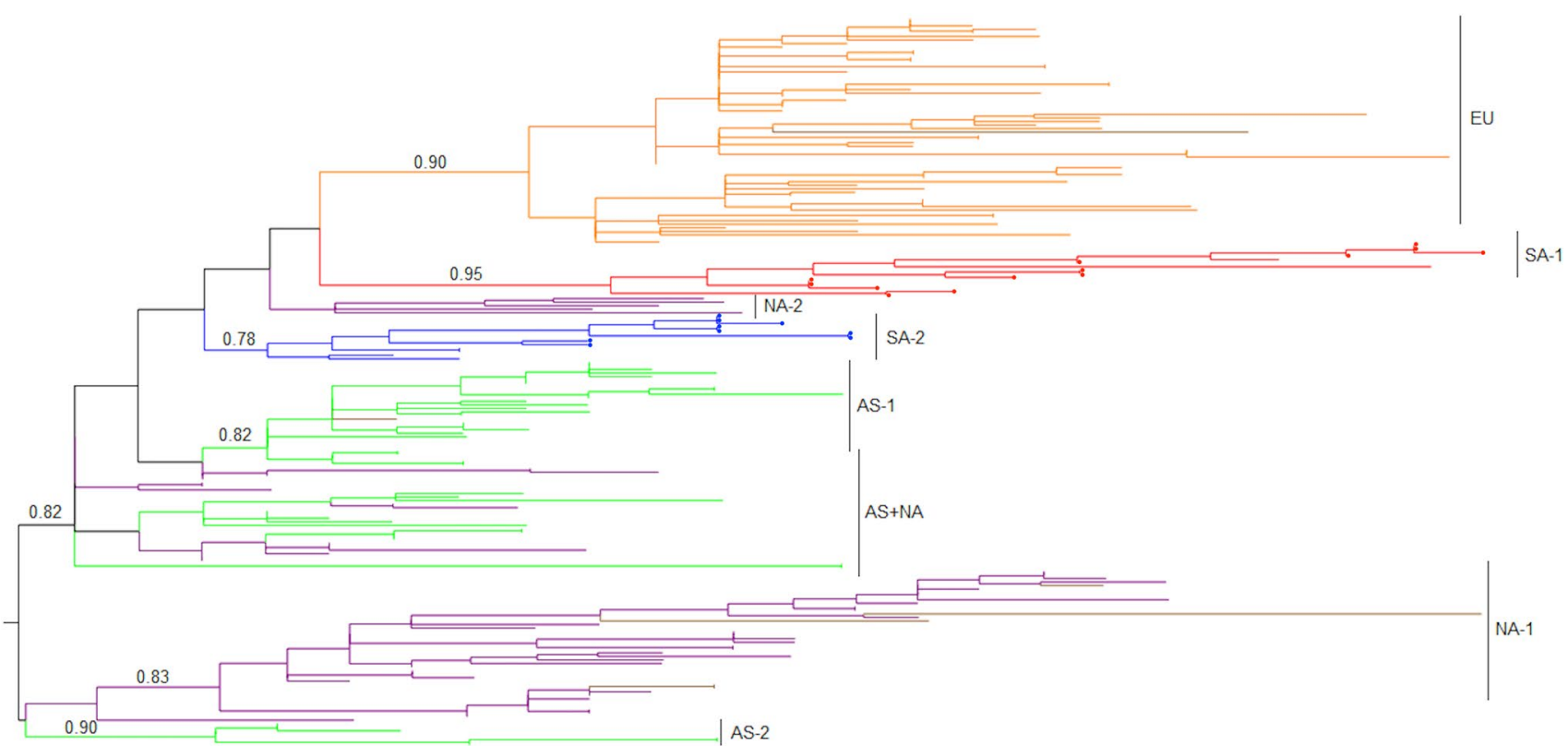

Fig. 3 Phylogenetic analysis. A maximum-likelihood tree was constructed with TIM3 plus gamma plus invariant sites as the nucleotide substitution model. Uruguayan strains from this study are indicated by red and blue circles, and the Mebus strain is indicated by a black circle. aLRT values at key branches and continent-specific lineages are shown. Branches are colored according to the continent of strain isolation: orange (EU), purple (NA), green (AS), red (SA, lineage with Argentinean strains), blue (SA, lineage with Brazilian strains), and brown (strains from a continent of isolation different from the continent-specific lineage). AS, Asia; EU, Europe; NA, North America; SA, South America

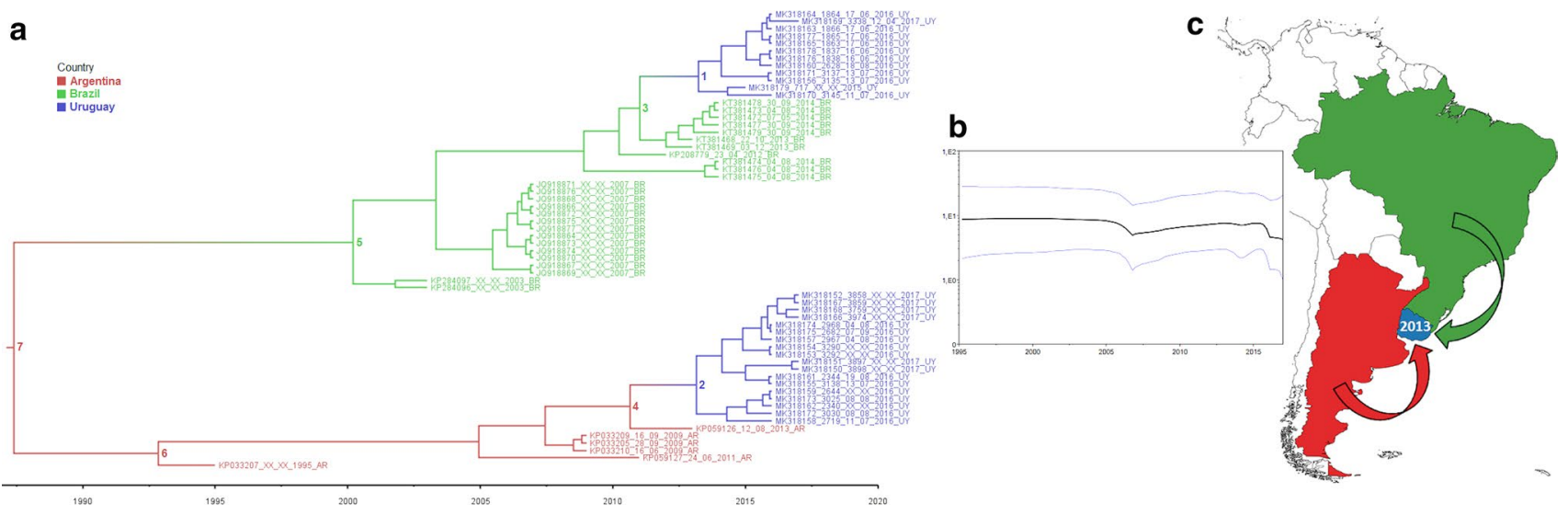

Fig. 4 Phylogeographic analysis. a) Maximum clade credibility tree. Branches are colored by most probable country location: blue for Uruguay, green for Brazil, and red for Argentina. Key nodes 1-7 are indicated (for which more information is available in Table 2). b) Population dynamics of BCoV in South America. The Bayesian sky-

\section{Signature patterns distinguishing Uruguayan lineages}

Four amino acid (aa) differences between the two BCoV lineages circulating in Uruguay were detected. These changes were N44D, A46S, S62T and Y77H (positions refer to the partial sequences used for the analysis). When line plot shows the evolution in population size. Median (dark line) and upper and lower 95\% HPD (blue lines) estimates of effective population size ( $y$-axis) through time in years ( $x$-axis) are shown. c) The two entries of $\mathrm{BCoV}$ to Uruguay in 2013 are indicated with arrows: red from Argentina and green from Brazil

the Uruguayan BCoV sequences were compared with the Mebus reference strain, six aa changes (4.0\%) were observed in all the Uruguayan strains, and three additional aa changes were observed, totalizing nine aa changes (5.4\%), with more than $75 \%$ of the Uruguayan sequences containing these changes (Fig. 5). 
Table 2 Key nodes for the information shown in Fig. 4

\begin{tabular}{lllll}
\hline Node & Country & Year & $95 \%$ HPD year & $\begin{array}{l}\text { Country } \\
\text { probability }\end{array}$ \\
\hline 1 & Uruguay & 2013 & $2011-2014$ & 0.99 \\
2 & Uruguay & 2013 & $2010-2014$ & 0.99 \\
3 & Brazil & 2011 & $2008-2012$ & 0.99 \\
4 & Argentina & 2010 & $2007-2012$ & 0.81 \\
5 & Brazil & 2000 & $1994-2002$ & 0.99 \\
6 & Argentina & 1992 & $1985-1994$ & 0.97 \\
7 & Argentina & 1987 & $1966-1994$ & 0.72 \\
\hline
\end{tabular}

\section{Discussion}

NCD can be associated with more than $50 \%$ of fatalities in calves [6]. Although multiple factors are involved, $\mathrm{BCoV}$ is one of the various pathogens associated with this syndrome. The cattle industry is one of the main sources of income in Uruguay, and this country is one of the main exporters of meat and dairy products worldwide [7-9]. In this work, we demonstrate the circulation of $\mathrm{BCoV}$ in calves in Uruguay, with a frequency of $7.8 \%$, which is higher than in Argentina (1.71\%) [18] but lower than in Brazil (14.9 - 33.3\%) [17, 27, 28].

The frequency of $\mathrm{BCoV}$ detection was higher in beef catthe than dairy cattle, in contrast to what has been reported in Argentina [18], although the difference observed in our study was not statistically significant. Moreover, it is worth mentioning that the sampling was not evenly distributed because many more samples were analyzed from dairy calves (782) than from beef calves (42). In addition, dairy cattle are concentrated in the southwest region of the country, whereas beef cattle are dispersed throughout the rest of the country [7]. Despite the difference in sampling, we considered the inclusion of beef cattle samples relevant, but the results should be interpreted with caution. We could not determine if the observed differences were due to the breed of cattle, calf management, production type and/or geographical region, so further studies are needed to clarify these points.

\begin{tabular}{|c|c|c|c|c|c|c|c|c|c|c|c|c|c|c|c|c|c|c|c|c|c|c|c|c|c|}
\hline & 455 & 457 & 458 & 462 & 465 & 470 & 484 & 492 & 494 & 495 & 499 & 501 & 503 & 510 & 514 & 525 & 528 & 531 & 533 & 543 & 544 & 545 & 571 & 578 & 589 \\
\hline Mebus & $\mathrm{T}$ & $Q$ & $\mathrm{~F}$ & $\mathrm{P}$ & $\mathrm{V}$ & $\mathrm{H}$ & $S$ & D & $S$ & $\mathrm{~L}$ & $\mathrm{~N}$ & $\mathrm{P}$ & 1 & $S$ & $\mathrm{~T}$ & $\mathrm{H}$ & $\mathrm{A}$ & $\mathrm{N}$ & $\mathrm{L}$ & $S$ & $\mathrm{~T}$ & G & $Y$ & $\mathrm{~T}$ & $\mathrm{~V}$ \\
\hline MK318162 & I & . & 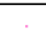 & . & . & $D$ & $T$ & $\mathrm{~N}$ & $A$ & . & $S$ & $S$ & 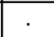 & . & 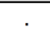 & $\bar{Y}$ & . & $\mathrm{D}$ & $\mathrm{M}$ & $A$ & . & W & $\mathrm{H}$ & 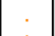 & ${ }^{\circ}$ \\
\hline MK318161 & . & . & $S$ & . & A & D & $T$ & $\mathrm{~N}$ & A & . & $S$ & $S$ & 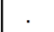 & . & . & $Y$ & . & D & M & A & . & . & $\mathrm{H}$ & I & 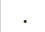 \\
\hline MK318159 & I & . & & . & & D & $\mathrm{T}$ & $\mathrm{N}$ & A & 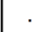 & $S$ & $S$ & 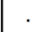 & . & . & $Y$ & 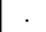 & D & M & A & . & W & $\mathrm{H}$ & . & 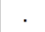 \\
\hline MK318175 & . & . & S & . & A & D & $\mathrm{T}$ & $\mathrm{N}$ & A & . & S & $S$ & . & . & . & $Y$ & . & D & . & A & . & . & $\mathrm{H}$ & I & . \\
\hline MK318158 & . & . & S & . & A & $\mathrm{D}$ & $\mathrm{T}$ & $\mathrm{N}$ & A & . & S & $S$ & 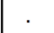 & . & . & $Y$ & . & D & M & A & . & W & $\mathrm{H}$ & . & $\cdot$ \\
\hline MK318157 & . & . & S & . & A & D & $\mathrm{T}$ & $\mathrm{N}$ & A & . & $S$ & $S$ & . & . & . & $Y$ & 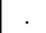 & D & . & A & . & . & $\mathrm{H}$ & I & . \\
\hline MK318174 & . & . & S & . & A & D & $\mathrm{T}$ & $\mathrm{N}$ & A & . & S & $\mathrm{S}$ & . & . & . & $\mathrm{Y}$ & . & D & - & A & . & . & $\mathrm{H}$ & I & . \\
\hline MK318173 & 1 & . & & . & & D & $\mathrm{T}$ & $\mathrm{N}$ & A & . & $\mathrm{S}$ & $\mathrm{S}$ & 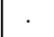 & . & $\cdot$ & $\mathrm{Y}$ & 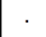 & D & M & A & . & W & $\mathrm{H}$ & . & 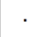 \\
\hline MK318172 & I & . & & . & A & $\mathrm{D}$ & $\mathrm{T}$ & $\mathrm{N}$ & A & . & $S$ & $S$ & . & . & . & $Y$ & . & $\mathrm{D}$ & M & $?$ & . & W & $\mathrm{H}$ & . & . \\
\hline MK318166 & . & . & $\mathrm{S}$ & . & A & $\mathrm{D}$ & $\mathrm{T}$ & $\mathrm{N}$ & A & . & $S$ & $\mathrm{~S}$ & 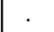 & . & 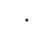 & $Y$ & . & $\mathrm{D}$ & 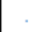 & A & . & . & $\mathrm{H}$ & I & $\mathrm{F}$ \\
\hline MK318167 & . & . & S & . & A & D & $\mathrm{T}$ & $\mathrm{N}$ & A & 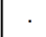 & $\mathrm{S}$ & $\mathrm{F}$ & 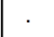 & . & $\cdot$ & $\mathrm{Y}$ & - & D & . & A & $\cdot$ & . & $\mathrm{H}$ & I & . \\
\hline MK318168 & . & . & $S$ & . & A & $\mathrm{D}$ & $\mathrm{T}$ & $\mathrm{N}$ & A & . & $S$ & $S$ & . & . & . & $\mathrm{Y}$ & . & $\mathrm{D}$ & 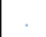 & A & . & . & $\mathrm{H}$ & I & . \\
\hline MK318155 & . & . & $S$ & . & A & $\mathrm{D}$ & $\mathrm{T}$ & $\mathrm{N}$ & A & . & $S$ & $\mathrm{~S}$ & 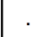 & . & . & $Y$ & . & $\mathrm{D}$ & M & A & . & . & $\mathrm{H}$ & I & . \\
\hline MK318154 & . & $P$ & & . & A & D & $\mathrm{T}$ & $\mathrm{N}$ & A & . & $\mathrm{S}$ & $\mathrm{S}$ & . & . & 1 & $\mathrm{Y}$ & V & $\mathrm{D}$ & . & A & . & . & $\mathrm{H}$ & . & . \\
\hline MK318153 & . & . & & . & A & D & $\mathrm{T}$ & $\mathrm{N}$ & A & . & S & $\mathrm{S}$ & . & . & I & $Y$ & V & $\mathrm{D}$ & . & A & . & . & $\mathrm{H}$ & . & . \\
\hline MK318152 & . & . & S & . & A & $\mathrm{D}$ & $\mathrm{T}$ & $\mathrm{N}$ & A & 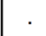 & $S$ & $\mathrm{~F}$ & . & . & . & $Y$ & 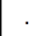 & $\mathrm{D}$ & . & A & . & . & $\mathrm{H}$ & । & . \\
\hline MK318151 & . & . & S & . & A & D & $\mathrm{T}$ & $\mathrm{N}$ & A & . & $S$ & $\mathrm{~S}$ & . & . & . & $Y$ & . & D & M & A & . & . & $\mathrm{H}$ & I & . \\
\hline MK318150 & . & . & $\mathrm{S}$ & . & A & $\mathrm{D}$ & $\mathrm{T}$ & $\mathrm{N}$ & A & . & $\mathrm{S}$ & $\mathrm{S}$ & & . & . & $Y$ & . & $\mathrm{D}$ & $\mathrm{M}$ & A & 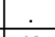 & . & $\mathrm{H}$ & I & . \\
\hline MK318178 & . & . & $S$ &. & $A$ & $D$ & $T$ & . & . & . & $S$ & $\mathrm{~S}$ & $T$ & $T$ & . & . &. & $\mathrm{D}$ & . & $A$ & $\mathrm{~K}$ & . & $\mathrm{H}$ & 1 & - \\
\hline MK318176 & . & . & S & . & A & D & $\mathrm{T}$ & . & . & . & $S$ & $S$ & $\mathrm{~T}$ & $\mathrm{~T}$ & . & . & . & $\mathrm{D}$ & . & $A$ & K & . & $\mathrm{H}$ & I & . \\
\hline MK318165 & . & . & & . & A & D & $\mathrm{T}$ & . & . & 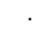 & $S$ & S & . & $\mathrm{T}$ & . & . & . & D & . & A & K & . & $\mathrm{H}$ & I & . \\
\hline MK318164 & . & . & . & . & A & D & $\mathrm{T}$ & . & . & ${ }^{\circ}$ & S & $S$ & . & $\mathrm{T}$ & $\cdot$ & . & . & $\mathrm{D}$ & . & A & K & . & $\mathrm{H}$ & I & . \\
\hline MK318177 & . & . & & . & A & $D$ & $\mathrm{~T}$ & . & . & 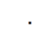 & $S$ & $S$ & . & $\mathrm{T}$ & . & . & . & $\mathrm{D}$ & . & A & K & . & $\mathrm{H}$ & I & . \\
\hline MK318169 & . & . & S & . & A & D & $\mathrm{T}$ & . & 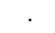 & . & $S$ & S & . & $\mathrm{T}$ & . & . & . & D & 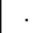 & A & K & . & $\mathrm{H}$ & I & . \\
\hline MK318156 & . & . & S & . & A & D & $\mathrm{T}$ & $?$ & $?$ & $\cdot$ & S & S & . & $?$ & $\cdot$ & $\cdot$ & . & D & $?$ & A & . & . & $\mathrm{H}$ & I & . \\
\hline MK318163 & . & . & & . & A & $D$ & $\mathrm{~T}$ & . & . & - & $S$ & $S$ & . & $\mathrm{T}$ & . & . & . & $D$ & . & $A$ & K & . & $\mathrm{H}$ & । & . \\
\hline MK318160 & . & . & . & . & A & D & $\mathrm{T}$ & ${ }^{\circ}$ & . & . & S & $S$ & . & $\mathrm{T}$ & ( & ${ }^{\circ}$ & . & D & . & A & K & . & $\mathrm{H}$ & I & $\cdot$ \\
\hline MK318171 & . & $\cdot$ & S & $\mathrm{H}$ & A & D & $\mathrm{T}$ & . & . & V & S & S & $\cdot$ & $\mathrm{T}$ & ${ }^{\circ}$ & $\cdot$ & . & D & . & A & . & $\cdot$ & $\mathrm{H}$ & I & - \\
\hline MK318170 & I & . & $S$ & . & A & $D$ & $T$ & . & . & . & $S$ & $S$ & . & $\mathrm{T}$ & . & . & . & D & . & . & . & . & $\mathrm{H}$ & I & . \\
\hline MK318179 & 1 & . & S & 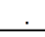 & $\mathrm{S}$ & $\mathrm{D}$ & $T$ & & 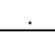 & . & $S$ & $S$ & & $\mathrm{~T}$ & . & . & . & D & 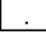 & $\mathrm{A}$ & & . & $\mathrm{H}$ & 1 & \\
\hline
\end{tabular}

Fig.5 Amino acid sequence alignment. Comparisons were done between the Mebus strain and the Uruguayan strains, and also between the two lineages circulating in Uruguay. Accession numbers of Uruguayan strains related to Argentinian and Brazilian strains are shown in red and green, respectively. The Mebus strain sequence was used as a reference. Numbers above the amino acid sequence indicate the position of the complete spike sequence of strain Mebus (accession number: U00735). Dots indicate conserved positions, and amino acid changes are represented using the corresponding one-letter symbol. Positions with more than $80 \%$ of strains containing differences are indicated by squares. Red, $100 \%$ of Uruguayan strains different from Mebus; orange, $>75 \%$ of Uruguayan strains different from Mebus; pink, $>50 \%$ of Uruguayan strains different from Mebus; dark blue, $100 \%$ of strains with differences between lineages; in light blue, $>50 \%$ of strains with differences between lineages, black, and other changes 
Strategies to prevent NCD should be directed toward enhancing host immunity and reducing the viral load in the environment [29]. There is evidence that the latter goal is not being met in Uruguay [30]; however, vaccination against NCD is a strategy used to enhance host immunity ( $48 \%$ of the calves in dairy farms in this study were born to vaccinated dams, Table 1). Interestingly, we observed that vaccination of the dam was associated with a reduced likelihood of $\mathrm{BCoV}$ being detected in the calves. It is important to clarify that the information collected about vaccination in this study refers to vaccination against NCD and not specifically against $\mathrm{BCoV}$, and although most vaccines include a strain of $\mathrm{BCoV}$, there are some exceptions. Therefore, the impact of vaccines on the reduction of $\mathrm{BCoV}$ needs to be investigated further. On the other hand, $\mathrm{BCoV}$ detection was higher in dead calves with diarrhea than in live calves (although not statistically significant), in concordance with previous data [31].

Interestingly, the frequency of $\mathrm{BCoV}$ detection and the proportion of diarrheic to non-diarrheic samples containing the virus varied with the age of the calves. While the frequency of $\mathrm{BCoV}$ detection was higher from the third week of age, the higher frequency of $\mathrm{BCoV}$ detection in diarrheic calves than in non-diarrheic calves was only observed in the first week of life. Colostral antibodies persist in calves for approximately 3 weeks, and between the third and fourth week of age, antibody titers from passive transfer are low, and the calf is just beginning to mount its own antibody responses to environmental microbiota [32]. The higher frequency of $\mathrm{BCoV}$ detection in the third and fourth weeks of age in our study might correspond to this decline in colostral immunity. On the other hand, the only age group with a higher $\mathrm{BCoV}$ detection rate in diarrheic samples than in nondiarrheic samples was the first week of age, in agreement with previous studies in which the susceptibility of calves to NCD caused by $\mathrm{BCoV}$ was found to be higher in the first days of life [33-36].

Notably, BCoV was detected mainly in the coldest months. Since $\mathrm{BCoV}$ is more stable at lower temperatures and lower levels of ultraviolet light [37], this might be a reason why $\mathrm{BCoV}$ is most frequently detected in winter [38, 39]. In Uruguay, according to the Uruguayan Institute of Meteorology (INUMET), in June, July and August (in addition to the temperature), the time of direct insolation, the vapor pressure, and the cumulative rainfall are also lower than in the other months, and the average relative humidity and the atmospheric pressure are higher than in the remainder of the months. Therefore, although we focused on the average temperature in this report, some (or all) of the above-mentioned factors could have been involved in the higher detection rate of $\mathrm{BCoV}$ in those three months. The higher frequency of $\mathrm{BCoV}$ detection in winter may be due to cattle shedding the virus year after year in the winter months, as the incidence of coronavirus shedding in nonvaccinated cows that delivered in the winter months has been reported to increase at parturition [38]. Calves born to $\mathrm{BCoV}$ carrier dams have a significantly higher risk of developing $\mathrm{BCoV}$-induced diarrhea due to periparturient exposure from fecal contamination, and if calves are raised in groups, transmission between them is expected [31, 38, 40, 41].

Although only one serotype of $\mathrm{BCoV}$ has been identified, there is increasing evidence of divergence of recent isolates from the historical reference strain used for most vaccine formulations (Mebus strain) [18, 42, 43]. In this regard, the strains detected in this study are divergent from the Mebus strain, as observed in the phylogenetic analysis, and nine amino acid differences were observed between the Uruguayan strains and Mebus. Four of these differences (together with several nucleotide changes, not shown), are associated with divergence between the Uruguayan lineages, although both appear to have entered to Uruguay in the same year and from neighboring countries. Surveillance is necessary to determine if vaccine strains are still effective against the new variants that are emerging, and if strains are found to have antigenic differences, they should be studied and possibly included in the vaccine formulations. Uruguayan $\mathrm{BCoV}$ strains that diverged from the Mebus strain were found to cluster with the Argentinean isolate Arg95. Mebus-induced neutralizing antibodies were capable of neutralizing the Arg95 strain and vice versa, indicating that the aa differences were not enough to establish a new serotype [18]. It is worth mentioning that some strains $(56 \%, 34 / 60)$ could not be amplified by conventional PCR, despite the fact that they were detected in positive samples by real-time PCR, which could be explained by a difference in the sensitivity of the methods and/or possible mutations in the primer regions.

Bayesian MCCT confirmed the two lineages circulating in Uruguay that were identified in the ML tree. One of the lineages entered from Argentina, and the other entered from Brazil, and both lineages entered in the same year (2013), which strongly suggests that there are biosecurity shortcomings leading to the transboundary spread of $\mathrm{BCoV}$ between these countries. However, factors that may have led to the introduction of these two viral lineages in the same year from two neighboring countries remain largely unknown. The substitution rate estimated in this analysis was $1.39 \times 10^{-3} \mathrm{~s} / \mathrm{s} / \mathrm{y}$, faster than previous estimates: $6.1 \times 10^{-4}$ s/s/y [44] and $8.7 \times 10^{-4} \mathrm{~s} / \mathrm{s} / \mathrm{y}$ [45]. Both previous analyses were carried out using complete $\mathrm{S}$ gene sequences (the first together with other betacoronavirus 1), while in our analysis, partial S genome sequences corresponding to a hypervariable region were used, which is expected to show a faster evolutionary rate and could explain this difference. The MRCA of the BCoV lineages circulating in South America was dated to 1987, and both lineages have been circulating for approximately 20 years on this continent: one of them 
in Argentina since 1992, and the other in Brazil since 2000, both spreading later to Uruguay. Based on our analyses, since the entry of $\mathrm{BCoV}$ lineages into South America, the population size seems to have been constant, although low fluctuations can be observed.

\section{Conclusions}

The two lineages of $\mathrm{BCoV}$ detected in this study have been circulating in Uruguayan cattle since 2013, on both beef and dairy farms. BCoV-positive calves in their first week of life are more likely to have diarrhea than older BCoV-positive calves. Winter months with lower temperatures were associated with a higher frequency of $\mathrm{BCoV}$ detection. Field $\mathrm{BCoV}$ strains in Uruguay are not divergent enough from reference vaccine strains to affect their antigenicity, suggesting that vaccination with currently available vaccines could represent an effective $\mathrm{BCoV}$ control strategy, although surveillance should be maintained to detect possible emerging strains that could diverge at the antigenic level from vaccine strains. Biosafety capabilities and biosecurity shortcomings between South American countries should be further assessed.

Acknowledgements This work was supported by the "Instituto Nacional de Investigación Agropecuaria" (INIA) [grant PL_015 N-15156]; and the "Universidad de la República" [program "Polo de Desarrollo Universitario"]. MC and RDC acknowledge support from "Agencia Nacional de Investigación e Innovación" (ANII) through PhD and MSc scholarships, respectively.

\section{Compliance with ethical standards}

Conflict of interest The authors declare that they have no conflict of interest.

\section{References}

1. Clark MA (1993) Bovine coronavirus. Br Vet J 149(1):51-70

2. Waltner-Toews D, Martin SW, Meek AH (1986) The effect of early calfhood health status on survivorship and age at first calving. Can J Vet Res 50(3):314-317

3. Donovan GA, Dohoo IR, Montgomery DM, Bennett FL (1998) Calf and disease factors affecting growth in female Holstein calves in Florida, USA. Prev Vet Med 33(1-4):1-10

4. Østerås O, Solbu H, Refsdal AO, Roalkvam T, Filseth O, Minsaas A (2007) Results and evaluation of thirty years of health recordings in the Norwegian dairy cattle population. J Dairy Sci 90(9):4483-4497

5. Windeyer MC, Leslie KE, Godden SM, Hodgins DC, Lissemore KD, LeBlanc SJ (2014) Factors associated with morbidity, mortality, and growth of dairy heifer calves up to 3 months of age. Prev Vet Med 113(2):231-240

6. Urie NJ, Lombard JE, Shivley CB, Kopral CA, Adams AE, Earleywine TJ, Olson JD, Garry FB (2018) Preweaned heifer management on US dairy operations: Part V. Factors associated with morbidity and mortality in preweaned dairy heifer calves. J Dairy Sci 101(10):9229-9244

7. DIEA (2018) Anuario estadístico agropecuario. https://descargas. mgap.gub.uy/DIEA/Anuarios/Anuario2018/Anuario_2018.pdf

8. Food and Agriculture Organization of the United Nations (2018) Meat Market Review, April. FAO, Rome

9. International Dairy Federation (2013) The world dairy situation 2013. Bulletin of the International Dairy Federation 470/2013

10. ICTV (2018) Coronaviridae. EC 50, Washington, DC, July 2018. https://talk.ictvonline.org/ictv-reports/ictv_9th_report/positivesense-rna-viruses-2011/w/posrna_viruses/222/coronaviridae

11. Alekseev KP, Vlasova AN, Jung K, Hasoksuz M, Zhang X, Halpin R, Wang S, Ghedin E, Spiro D, Saif LJ (2008) Bovine-like coronaviruses isolated from four species of captive wild ruminants are homologous to bovine coronaviruses, based on complete genomic sequences. J Virol 82(24):12422-12431

12. Giannitti F, Diab S, Mete A, Stanton JB, Fielding L, Crossley B, Sverlow K, Fish S, Mapes S, Scott L, Pusterla N (2015) Necrotizing enteritis and hyperammonemic encephalopathy associated with equine coronavirus infection in equids. Vet Pathol 52(6):1148-1156

13. Masters PS, Perlman S (2013) Coronaviridae. In: Knipe DM, Howley PM, Cohen JI, Griffin DE, Lamb RA, Martin MA, Racaniello VR, Roizman B (eds) Fields virology, 6th edn. Lippincott Williams and Wilkins, Philadelphia

14. King B, Brian DA (1982) Bovine coronavirus structural proteins. J Virol 42(2):700-707

15. Lai MM, Cavanagh D (1997) The molecular biology of coronaviruses. Adv Virus Res 48:1-100

16. Cavanagh D (1995) The coronavirus surface glycoprotein. In: Siddell SG (ed) The Coronaviridae. The viruses. Springer, Boston

17. Brandão PE, Gregori F, Richtzenhain LJ, Rosales CA, Villarreal LY, Jerez JA (2006) Molecular analysis of Brazilian strains of bovine coronavirus $(\mathrm{BCoV})$ reveals a deletion within the hypervariable region of the $\mathrm{S} 1$ subunit of the spike glycoprotein also found in human coronavirus OC43. Arch Virol 151(9):1735-1748

18. Bok M, Miño S, Rodriguez D, Badaracco A, Nuñes I, Souza SP, Bilbao G, Louge Uriarte E, Galarza R, Vega C, Odeon A, Saif LJ, Parreño V (2015) Molecular and antigenic characterization of bovine Coronavirus circulating in Argentinean cattle during 1994-2010. Vet Microbiol 181(3-4):221-229

19. Beuttemmuller EA, Alfieri AF, Headley SA, Alfieri AA (2017) Brazilian strain of bovine respiratory coronavirus is derived from dual enteric and respiratory tropism. Genet Mol Res. https://doi. org/10.4238/gmr16029580

20. Kumar S, Stecher G, Tamura K (2016) MEGA7: Molecular evolutionary genetics analysis version 7.0 for bigger datasets. Mol Biol Evol 33(7):1870-1874

21. Trifinopoulos J, Nguyen LT, von Haeseler A, Minh BQ (2016) W-IQ-TREE: a fast online phylogenetic tool for maximum likelihood analysis. Nucleic Acids Res 44(W1):W232-W235

22. Anisimova M, Gascuel O (2006) Approximate likelihood-ratio test for branches: a fast, accurate, and powerful alternative. Syst Biol 55(4):539-552

23. Rambaut A, Lam TT, Max Carvalho L, Pybus OG (2016) Exploring the temporal structure of heterochronous sequences using TempEst (formerly Path-O-Gen). Virus Evol 2(1):vew007

24. Tamura K, Nei M (1993) Estimation of the number of nucleotide substitutions in the control region of mitochondrial DNA in humans and chimpanzees. Mol Biol Evol 10(3):512-526

25. Drummond AJ, Suchard MA, Xie D, Rambaut A (2012) Bayesian phylogenetics with BEAUti and the BEAST 1.7. Mol Biol Evol 29(8):1969-1973

26. Korber B, Myers G (1992) Signature pattern analysis: a method for assessing viral sequence relatedness. AIDS Res Hum Retroviruses 8(9):1549-1560 
27. Stipp DT, Barry AF, Alfieri AF, Takiuchi E, Amude AM, Alfieri AA (2009) Frequency of BCoV detection by a semi-nested PCR assay in faeces of calves from Brazilian cattle herds. Trop Anim Health Prod 41(7): 1563-1567

28. de Mira Fernandes A, Brandão PE, Dos Santos Lima M, de Souza Nunes Martins M, da Silva TG, da Silva Cardoso Pinto V, de Paula LT, Vicente MES, Okuda LH, Pituco EM (2018) Genetic diversity of BCoV in Brazilian cattle herds. Vet Med Sci. https:// doi.org/10.1002/vms3.102

29. Gomez DE, Weese JS (2017) Viral enteritis in calves. Can Vet J 58(12):1267-1274

30. Castells M, Schild C, Caffarena D, Bok M, Giannitti F, Armendano J, Riet-Correa F, Victoria M, Parreño V, Colina R (2018) Prevalence and viability of group A rotavirus in dairy farm water sources. J Appl Microbiol 124(3):922-929

31. Blanchard PC (2012) Diagnostics of dairy and beef cattle diarrhea. Vet Clin N Am Food Anim Pract 28(3):443-464

32. Hulbert LE, Moisá SJ (2016) Stress, immunity, and the management of calves. J Dairy Sci 99(4):3199-3216

33. Murphy FA, Gibbs EPJ, Horzinek MC, Studdert MJ (1999) Coronaviridae. Veterinary virology, 3rd edn. Academic Press, New York

34. Svensson C, Lundborg K, Emanuelson U, Olsson SO (2003) Morbidity in Swedish dairy calves from birth to 90 days of age and individual calf-level risk factors for infectious diseases. Prev Vet Med 58(3-4):179-197

35. Cho YI, Han JI, Wang C, Cooper V, Schwartz K, Engelken T, Yoon KJ (2013) Case-control study of microbiological etiology associated with calf diarrhea. Vet Microbiol 166(3-4):375-385

36. Cho YI, Yoon KJ (2014) An overview of calf diarrhea-infectious etiology, diagnosis, and intervention. J Vet Sci 15(1):1-17

37. Evermann JF, Benfield DA (2001) Coronaviral infections. In: Williams ES, Barker IK (eds) Infectious diseases of wild mammals, 3rd edn. Iowa State University Press, Ames, pp 245-253
38. Collins JK, Riegel CA, Olson JD, Fountain A (1987) Shedding of enteric coronavirus in adult cattle. Am J Vet Res 48(3):361-365

39. Mawatari T, Hirano K, Ikeda H, Tsunemitsu H, Suzuki T (2014) Surveillance of diarrhea-causing pathogens in dairy and beef cows in Yamagata Prefecture, Japan from 2002 to 2011. Microbiol Immunol 58(9):530-535

40. Boileau MJ, Kapil S (2010) Bovine coronavirus associated syndromes. Vet Clin N Am Food Anim Pract 26(1):123-146

41. Bulgin MS, Ward AC, Barrett DP, Lane VM (1989) Detection of rotavirus and coronavirus shedding in two beef cow herds in Idaho. Can Vet J 30(3):235-239

42. Gunn L, Collins PJ, O'Connell MJ, O’Shea H (2015) Phylogenetic investigation of enteric bovine coronavirus in Ireland reveals partitioning between European and global strains. Ir Vet J 68:31

43. Fulton RW, Herd HR, Sorensen NJ, Confer AW, Ritchey JW, Ridpath JF, Burge LJ (2015) Enteric disease in postweaned beef calves associated with Bovine coronavirus clade 2. J Vet Diagn Investig 27(1):97-101

44. Vijgen L, Keyaerts E, Lemey P, Maes P, Van Reeth K, Nauwynck H, Pensaert M, Van Ranst M (2006) Evolutionary history of the closely related group 2 coronaviruses: porcine hemagglutinating encephalomyelitis virus, bovine coronavirus, and human coronavirus OC43. J Virol 80(14):7270-7274

45. Bidokhti MR, Tråvén M, Krishna NK, Munir M, Belák S, Alenius S, Cortey M (2013) Evolutionary dynamics of bovine coronaviruses: natural selection pattern of the spike gene implies adaptive evolution of the strains. J Gen Virol 94:2036-2049

Publisher's Note Springer Nature remains neutral with regard to jurisdictional claims in published maps and institutional affiliations. 